\title{
The Strange Case of the Misappearance of Sex in Videogames
}

\section{Tanya Krzywinska}

Over the past few years, the popular press has made considerable capital from couching criticisms of videogames in sensationalist rhetoric. One of the outfalls of the use of compellingly lurid rhetoric is the aggravation of fear; in this case the fear that games pose a significant threat to our peer-driven yet otherwise innocent children and teenagers, as well as more generally to our moral health and values. If the sensationalist rhetoric is believed the impression gained is that videogames are loaded with dangerous, corrupting violent and sexual imagery.

"Computer games will carry cinema-style age ratings to protect children from violent and sexual images, ministers said yesterday" reports Tanya Byron in response to a UK government commissioned report in 2007. Calls for greater regulation designed to gain the attention of the fearful are often served by yoking together sex and violence. British politics aside, this is a classic exploitation technique which thrives on lack of knowledge. Technology is presented as a portal through which will pour soul-eating terrors that threaten to undermine the pillars of civilization. Where violence or sex do appear in games, and why not as these both play a core role in human imagination and experience, all sense that these are mediated and often highly contextualised in either gameplay or narrative terms is lost (factors more likely to be taken into account in relation to the more established media such as film or television). For those looking for easy answers or wishing to exploit the fears of those without understanding, rhetorics of sensationalism enable games to be made responsible for the broader ills of society (Gauntlett 2005; Barker and Petley 2001).

And yet, the game industry has also benefited from sensationalist rhetoric in regard to sex, particularly in the perfumed promise of sexual utopia apparently offered by new digital and haptic technologies. During the 1980s, the term "teledildonics" fell like honey from the lips of the pre-blogging chattering classes. Promising a garden of delights, Virtual Sex emblemized the new frontier; throbbing and pulsating controllers provided only a tantalizing rumble of a future where bodies would be wired for perpetual orgasm, unfettered by relationships and STDs. The pledge of ecstatic presence fizzled however in the cold light of a hand full of pixels and a limited number of mechanized bleeps. Sexual promise is very often made in relation to new technologies, mobilized every time a new media, interface method or technological development is made, as for example transferred to Microsoft's hands-free interface, Kinect, after the amatory disappointments of the Wii controller.

One the most problematic aspects of sensationalist rhetoric when used as a tool to sway opinion is that it elides complexity. As psychoanalytic thought suggests, human sexuality is far from simply reproduction with imagination as important as physiology and drives. Working with the erotic imagination (which does not acknowledge in its inherent putative state limiting realities), sensationalist rhetoric regularly promises far more than it actually delivers. However, once we look for the loudly denounced and promised sex in games it is far less apparent than suggested. This point is very well made by Daniel Floyd's entertaining animated essay (2008) and Brenda Brathwaite makes a similar argument in her design-guide, Sex in Videogames (2007). However, Floyd and Brathwaite, as well as sensationalist claims, overlook a more subtle and erotic presence in gaming and games which this paper seeks to demonstrate.

My plan is to take a more sophisticated and theoretically-informed look at sex in games. While there is proportionally little sex in games in relation to other media, l'll begin by showing that some games do have explicit sexual imagery, a 
necessary step because it is important to ascertain the conventionalized types of rhetoric used within games to represent sex and sexual desire. Further, I aim to outline some of the context and conditions on which the explicit presence of sex seems to rest and as well as addressing the wider and more subtle libidinal economies of games - a term I have adapted for use in this essay that is borrowed from psychoanalysis generally and Lyotard specifically (1974). In a broader sense, such work is important if we are to move beyond the reductive model of "effects" theory. It is therefore a principal claim of this chapter that sex in games shouldn't be measured simply by the use of explicit sexual imagery. Broader concepts of sexuality and desire must be considered. I propose an approach to the study of sex and games that takes account of representation, rhetorics and conventions, game mechanics and the libidinal economies at work in games and the act of gaming. Working in concert, game computing and mechanics, story structures and representation constitute a game's aesthetic configuration and all must be considered when regarding our libidinal investment in games. I so doing I draw on concepts and models that provide a libidinal understanding of sex and desire. We'll start by examining some of the leading conventions used in the representation of sex in games, focusing on graphics and narrative. Going on to analyze the use of sex, overtly or implicitly, in terms of the design of game mechanics, followed by a concluding section arguing for a more diffuse and sophisticated understanding of the "erotics of games".

For something to be sexually "graphic" in visual, pornographic terms there has to be a certain level of detail so that the anatomical features involved in sex are apparent. Graphical fidelity is therefore important if an equivalent of a human body is to be constructed in a game - in fact the development of sex in games hinges on such. That is not to say that game bodies need to be depicted stylistically in a photographic way of course. Early 2D games managed to manipulate a few pixels to look like human breasts and erect penis in a highly crude graffiti-esque style. Mystiques' Custer's Revenge is an example (Fig. 1). The game's graphics are extremely "crude" in an over-determined way and arise in part from their 8-bit, exploitation production context (indeed Atari sued Mystique for defaming their brand); and while the intention might have been simply to garner attention through brutal crassness, the game's graphical crudeness makes explicit, through challenging rape imagery, the sexual agenda of American colonialism. Later developments in graphics technologies and particularly motion capture provide far greater expressive means in the representation of the sexual body. Bodies and their movements are more now far more refined and subtle, allowing games to drawn more readily on the types of images and representations of sex found in film-based media.

With the increased potential of graphics technologies, game bodies became tailored more tightly to please the gaze, although rarely do these idealized game bodies engage in sex. Susan Sontag (1967) that in written fiction designed to be consumed as pornography a style emerges where everything is exaggerated. The Marquis de Sade's stories for example are populated with huge male members and engorged female genitalia that overpower subjectivity and rationality. Silicone implants and the fashion for body building are keyed into such an exaggerated mode - coded as they are in and through fantasy and where tumescence and rigidity become an expressive form. Digitally produced bodies are sculpted straight from the imagination. Unencumbered by real-life physics, unrestricted by flesh and bones, game bodies are impossibly ideal. Yet, while anything is possible, a conventionalized and binarised picture emerges large-breasts, long legs and tiny waists for women, bulked-out muscles for men. Archetypal sexualized are deployed to create a seductive, connotation-based bestiary for the imagination to play with but which implicitly demonstrate the fallibility of and lack in our poor bodies.

Developments in graphics technologies allow designers and artists to create for players alluring characters, providing support for being-in-the-world of the game by providing for players objects of desire and aspiration. However, the 
muscled, the agile, and the powerful represent sex - they do not have sex. Governed by the economics of the ideal and the forward motion of games (see Atkins 2006), iconic characters act as our fetishes, objects that bring desire into existence to keep it in play and hungry, as a result sex itself must remain off-scene.

Fig. 1. From Pixels to Motion Capture: Custer's Revenge (1982) Screenshot

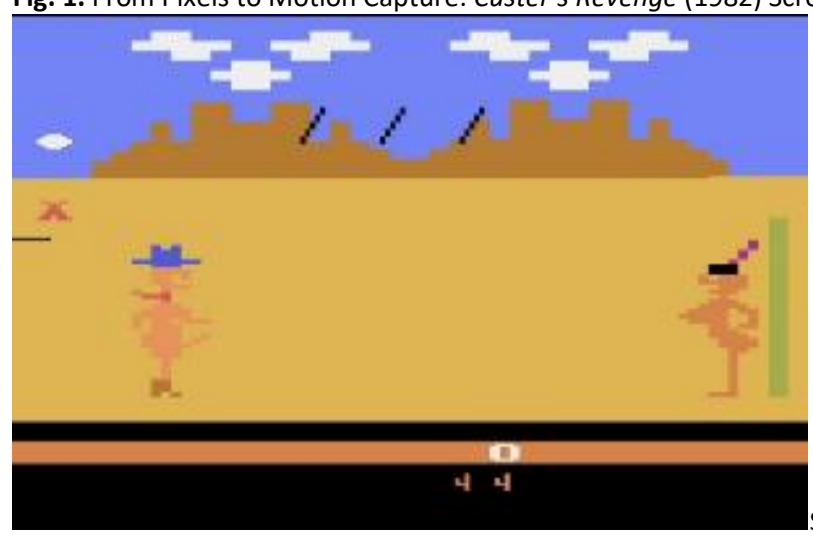

Source: $h t t p: / / l i s t v e r s e . f i l e s . w o r d p r e s s . c o m / 2008 / 04 / s-c u s t e r s r e v e n g e-1 . p n g$

Given that games promise "action", it is a little surprising that sex is rarely integral to game stories. Where sex is present it is likely to appear in a cut-scene. The Mass Effect games included short sex scenes presented mainly as cutscenes. There is some player choice however: depending on verb choices and on which character the player has chosen to play and who the player chooses to interact with. Players can elect for their player-character to have sex with humans or aliens and differently gender. For example, sex between male Shepherd and Liara, an alien, is a tender affair presented as an expression of intimacy and intensity. In many ways this pair conforms to the cinema equivalent of the "proper couple", except of course this is cross-species sex. Cut-scenes enable the game to draw on the visual vocabularies used within cinema. Various camera angles are can be utilized marking a different to the monolithic use of camera elsewhere. The framing pattern present the encounter between Shepherd and Liara in the first game as intimate and loving rather, using romance to legitimize the presence of sex. Implied sex through romantic liaison is common at the level of story in games, where sex tends to occupy back story. In an alternate scene in the first game between Ash (a human female) and Shepherd, the encounter is presented in terms of fun and playfulness (with a hint of S-M style power play), a pastime framed as affectionate but not seemingly an expression of deep romantic love or passion. A further permutation is one that occurs between Liara and a female Shepherd, again an intimate and passionate encounter, even if a classic pornographic trope designed mainly for male consumption. Importantly all these encounters fade to black - another cinematic convention - once the idea of what is happening is established, even more quickly in the case of those including the least human of the aliens.

Games draw on cinema, but game bodies are not those of actors - even if data on movement of real bodies is used. Lara Croft is made in the model of a pin-up but what does it mean to see her nude? Under the skin she's all wireframe reminding us that our libidinal relation with game characters is the product of technological adept illusion tailored, like Pygmalion's Galatea, to the consumer imagination. Lara's form, presenting a Sadean tumescent pornographic body in the pose of fifties cheesecake all tailored to the requirements of the action genre. We can't see Lara nude; only the representation/simulation of nudity, very different therefore from physically nude actors in live-action cinema. Nudity 
is carefully managed in cinema and games even if the status of nudity is very different. It might seem surprising but pre-Code Hollywood films presented a certain amount of nudity, presence, for example, in D.W. Griffith's Intolerance. With the implementation of greater regulation in the late 1920s, actresses' breasts where covered and framing and editing techniques used to suggest but elide the physical sexual body. Such suggestive yet elliptical techniques are often simulated in games, as the fade-to-black in Mass Effect games shows. The effect of the suggestive elision though plays towards exploitation, rendering sex more dangerous and seductive.

Story types and tropes are also borrowed from cinema (as well as other media) and, like many other forms of popular fiction, "romance" between two complementary people (class, race, age, aspiration etc) provides the condition that legitimizes the presence of sex; where this trope is missing sex becomes sensationalized or even unconscionable, a framework exploited by the Grand Theft Auto franchise. Romance also lends pathos in revenge or rescue scenarios but is rarely the major theme in the context of action-led games. Like film, many games also use the legitimizing and permissive effect of comedy, a framework that has often been used in popular culture to permit mention of sex and desire. Games are generally less focused on sex and romance than action however. It rare for games to show sex as tragic, traumatic or a form of self-empowerment, a trope found in softcore movies with female central protagonists such as Emmanuelle (1974) or Story of O (1975); although in Fable (2004) it does represent a rite of passage and helps to make the central character more rounded and believable. Symbolisation is another common and suggestive device borrowed from film and fictional forms - the "dance" of two adult pinatas seen in cut-scene as a prelude to the production of babies in Viva Pinata (2006) is a good example and one designed for children to play. Pre-existing vocabularies are therefore deployed in games. These range from those derived from mainstream, art and exploitation cinemas, as well as softcore and hardcore film. But, decisively, games also use sex in ways that extend beyond representation and narrative. It is to the place of sex as a game mechanic that I now turn.

It is helpful to make a distinction between games and virtual sex simulators (although the latter can be found in some games). While sex simulators have a relatively long history and are often found for free on the unregulated net, in terms of market and form they are not "games", even as they may have similar interfaces and use conventions found in games. Sex sims are generally designed to be consumed as exclusively porn, while the situation with games that incorporate sex within the sphere of game mechanics is more complex. Most of the games looked at here are those where sex is integral to their internal and external design.

PlayBoy: The Mansion (2005) has as its lead designer Brenda Brathwaite, an advocate of sexually explicit games for adults. The game is made under within the Playboy franchise, gamifying a well-known brand and making use of that brand to inform the game's representational dimensions. Social aspiration and a tongue-in-cheek humour prevail. In the guise of "Hef" (Hugh Hefner, the magazine's "playboy" owner), the player is tasked with building relationships with a range of visitors to his house in order to create copy (photos, articles and interviews) for a magazine. Progress is made by holding parties, getting women to pose nude for Hef/player's in-game camera and persuading minor celebrities to write for the magazine or be interviewed. In this way status and cash are accumulated - both overtly measured and keyed into the game's internal winning conditions. Mechanics borrow in part from The Sims mixed with the those of Tycoon series. A drive meter is visible to the player for each Non-playing character (NPC) providing a means by which a player can see how happy they are: the aim being to do what's keeps them happy. This is done by choosing from the various verbs provided by the game to compose a conducive conversation with those NPCs. Egosoothing bunnies aid Hef/player's passage through the social encounters thrown up by the game, although if they are neglected they will leave the mansion diminishing the players route to success. Prestigious people are attracted to parties once the player spends money on hipper furnishings and providing entertainment. Hef/player can also take 
photos of his well-managed female guests to place in his magazine. The player can cycle through various poses and site the model in a location with the click of a few buttons. The game also includes 'factoids' from the magazine's history and images of (real) past "playmates".

The game provides a highly regulated tease; sex is clearly the core theme and its most explicit articulation can be found when Hef/ player persuades a female NPC to have sex with him. The persuasion process takes a while but eventually sex ensues. The playstation handset vibrates to indicate orgasm as the woman sits astride Hef, whom we see in third person; her climax is comically (ridiculously) indicated by an in-situ backflip and a shout of "weeeee", as if she was on a fair ground ride. Both keep their pants on throughout, making naked breasts the focus of attention, as was mostly the case with the Playboy magazines. There are no sexually graphic cut-ins or close-ups of the type usual in hardcore film, inclusions that would place the game outside of regulatory systems. No risk is therefore taken with the franchise or investment. Women with whom player/Hef has built close relations are more likely to readily pose and have sex with him. Relationship building is therefore central even in the broader context of the business and commercialization of the sexual body. Sex here is unproblematic; that is once appropriate smoothing devices are deployed. As such sex becomes quantifiable, gamified, and, simultaneously, constructed as a normal activity partaken of by consenting adults without deep emotional or marital ties. If you know the rules of the game you can "make out" for pleasure and business. Playboy: The Mansion's version of sex is decided intended not to be read as perverse nor transgressive. By virtue of this formulation, Brathwaite is able to make a game where sex becomes part of the gameplay mechanics and actively uses symbols and ellipses to mark it off from "hardcore" pornography.

By contrast, 7 Sins (2005) takes a far less benign and normalising approach to sex. Here sex is associated with cynicism and transgression. Sex is certainly not legitimated by romance or even titillating playfulness. Unlike the Playboy game, the aim is not to manage the drives of others but your own. You play an "unrepressed" (sexually psychotic) man, and your task is to keep the player-character's "sin" bars topped up, never letting one drive overwhelm the others. It is a far less slick and well-designed game than high profile, big-budget Playboy: The Mansion, underlining thereby 7 Sins grimy, exploitation qualities. The main game arc is supplemented with various mini-games that are accessible at any time designed to help balance out the player-character's sin bars. Various possibilities are on offer: zooming in to "perv" portions of a cartoonish female body, stealing money from a woman's flat, and, perhaps the most bizarre minigame of the lot, is one designed to bring down the Anger bar where the player-character urinates into a potted plant, aiming the flow to swat flies. The verbs that govern the game's internal design are composed of transgressive actions such as "steal", "grope" or "perv", and in-game conversation options range from clichéd chat up lines to abuse. In the first level of the game, the player-character is tempted to transgress but compelled to manage his urges in order not to get fired from the shop where he is working. The odd good deed can be undertaken to re-balance close to bulging sin bars (the temptation for the player is to see what happens when the different sin bars maximize). The game's internal mechanic derives implicitly from a model of sexuality associated with unconscious drives, drawing on the powerful notion that the sexual drive is disruptive and compelling. This conceptualisation of sex is one that informs older pornographic fiction, such as de Sade's monstrous fornicators. It is also a model that is found in psychoanalysis and the Lapsarian notion of sex as shameful. As a cross-medial genre, exploitation makes its capital from precisely this transgressive notion of sex and sexual desire. In this sense a psychoanalytic model of sex as drive-based fits hand-inglove in games where there is a need for quantification; a drive model of sex can therefore be easily translated into gamic terms through a device such as a progress bar.

"We are puppets of our hormones and genetic programs. But nature repays us with pleasure" (Blackburn 2004, 125). 
The games I have mentioned above are rare in their explicit use of sex whether in or at play in representation and gameplay mechanics, yet we might approach the topic of sex and games in a more subtle way by looking closely at the libidinal economy of the player-game relationship in games where sex appears to be absent.

Playing games appears to be a very rational and controlled activity. Many theorists of games have defined games in terms of their rules and the need for players to manage their performance, considering these their defining condition. I have argued elsewhere that a great deal of the pleasure of playing games lies in the sensations and rewards associated with becoming a more skillful and prudently responsive player of a given game. But management through constraint is not the only pleasure game in town; games are more than just these and when addressing the erotics of play we have to take into account not simply rules as procedural elements of a game but more generally as part of a libidinal economy - to use Lyotard's evocative phrase (meaning the psychic and emotional energy produced by drives). In pursuit of understanding the libidinal economy of games our focus is on the relationship between the player and the game and game designers deploy a large variety of devices to please, tease and excite a player.

It has become quite common in text-based game studies analysis to regard games in terms of the verbs they proffer. As a means of aiding in the task to understand more deeply the pleasures of games, it seems helpful to also regard games in terms of adjectives. Appropriately these knit syntactically with a game's mechanical verbs making up a game's vocabulary. In chaining adjectives with verbs my aim here is to show how "doing'" in a game becomes libidinally charged. The particular grain of a given act couched within meaning-producing contextual qualifiers is designed to resonate and evocate. Actions in games are cyphers or metonyms, not full acts as would be the case in the real world, but instead actions made potent by imagination. Prompted by physical actions and the events on screen, the player conjures from memory and imagination what it feels like to be doing that action. The libidinal economy of game is then, in part, dependent on a creative engagement on the part of the player.

Below are listed verbs and adjectives that characterize our libidinal investment in games. Some of the words listed would be erotically charged in connection with any media, but some are specific to games and some are drawn from the work of critics as is the case with Espen Aarseth's evocative terms Aporia and Epiphany (1997). What is also notable here in terms of libidinal economics is that they all carry a sexual connotation, words that we might find used to describe in an artful yet nuanced description of a sexual encounter.

\begin{tabular}{ll}
\hline Expectation & Immersion \\
Intensity curves & $\begin{array}{l}\text { Bodily control-condensed move- } \\
\text { ments }\end{array}$ \\
Frustration/Aporia & Concentration/focus \\
Elation & Skillful \\
Release & Drive \\
\hline
\end{tabular}




\begin{tabular}{ll}
\hline Reward & Enigma/revelation \\
Feedback & Epiphany - 'aha' moments \\
\hline
\end{tabular}

For a moment I ask you to take up the position of an artist or lover, looking passionately and attentive to all the nuances of line, form and correspondence. Let's take Assassin's Creed (2007) as the object of such a mode of seeing other games are possible of course. In a general sense it the kinetic energy afforded to the player through the playercharacter, renegade Assassin Altair. The player-character can scramble up buildings, jump gaps between them, climb high pinnacles to survey the environment, as well as run, sneak and wield various weapons. All these actions are needed to progress through the game. What this verb-approach does not tell us is the qualities of how our pleasure in this is achieved. Throughout the game characters are built and designed around the use of motion-capture that lends them a nuanced and fluid mode of movement. This invests vitality, animating them so they do not act in stilted or repetitive ways. Characters also move through intensively, eye-arresting detailed environments. There are no clean horizon lines to be seen here or simple graphical planes, instead the eye dances across multilayered shapes, movements, colours and textures. Altair himself moves with ultimate confidence and grace in this world (it is after all measured precisely to his computational and graphical physics). He is also the embodiment of contradictions: conundrums that arrest the gaze and intrigue. He is extremely agile, leaping weightlessly across impossible voids, yet also steadily weighted with footfalls and arm movements seeming solid, connecting reassuringly with the world he so lithely inhabits. His chain mail presses downwards into his body, yet sits in juxtapositioned contrast with the fluidity of the light cotton tabard that dances around his legs, emphasizing his movement and linking him to the free and transcendent breeze. The eroticised kinetic power in the free-floating cloth provides for the player a characterization of Altair who moves in mysterious ways, particularly noticeable in cut-scene sequences where he leaps in faith from some precipitous minaret, leaving the player to wonder at his physical assurance. Exotic and distanced by strong thirdperson characterization, he is briefly ours to hold, a fetish in the sanctioning of our mesmerised gaze. The same attention to kinetic detail is also found in Altair's fighting animations. Taking on a group, he whirls like a dervish, sword flying in balletic arcs. Killing softly, his primary mode is quiet assassination: an act shown as at once tender and brutal. Slitting the throat of one victim with a spring-loaded blade hen then stroking closed the eyes of his victim. His veiled face, silky-assured movements, the noticeable physical contact with those he shoulders past or fights all work to evoke a complex, embodied and tactile presence.

What can also be said to be present in this characterization is a libidinal coherence around what psychoanalysis calls a phallic economy, more accurately pivoting around the eroticisation of the act of penetration. Sliding the knife in, slicing deep and intimately into the flesh of enemies, all this violent yet artful penetration balances with a more general economy of physical touch. There is therefore clearly an erotic dimension in play, perhaps just under the surface for some players, and of course as it is the player who puts the knife in they too are implicated in this erotic, violent danse macabre. A certain type of sexual currency is apparent, one that links penetration with domination, sharpened by his silken touch. This economy of domination is complex, forged on the anvil of homosociality, and brackets off any notion of penetrative sex as an expression of equality and intimacy. 
I am not the only one to note the erotic economy at work in games that are not apparently about sex. In a rather different way, Hanna Wirman (2010) noted the erotic encouragements of the deep-voiced male narrator in Bejewelled (2001), who encouragingly purrs the word "good", building to "excellent" and "awesome", at the player. Such sexualized encouragement sits alongside orgasmic explosions when lines are conjoined. This is a game that has proved extremely successful in the casual game market and may well have used such techniques to seduce a female market. In a more general sense the act of designing a game as an orchestrated experience of a player can also be regarded in the same way that a theatricalised fetish or sado-masochistic scene may be choreographed; both are designed to take the participant on a journey with the game/scene designer assigned power over the player/submissive through the contract of the game and who must submit to exacting demands.

According to Blackburn the definitions of lust is the "anticipation of pleasure" and the "pursuit of rapture" (2004, 16). These work equally well in describing playing a game. Designers aim to keep players playing - to tease them onward by constantly project players forward in time to what is yet to come (Atkins 2006). But many play to lose themselves in the heat of the moment, to feel the break in tension caused by the completion of a difficult task. Blackburn tells us lust is "desire that is felt, the storm that floods the body. That heats and boils and excites" $(2004,17)$. Gamers regularly speak of how they become immersed in a game, their perception of time distorted, suggesting that there is a link between a sense of immersion in a game and the medieval definition of ecstasy, where we transcend time and ourselves. While this might be a bridge too far for some who have a more prosaic approach to games, it is the case that games are loaded with textual seductions - prediction, revelation, progress, feedback as well as kinetic and audio-visual pleasures. Cybernetic qualities are also libidinal qualities which become evident in a player's synergic relationship with a game, mutual responses back and forth - a dance or conversation - much like the reciprocity of engaging in (good) consensual sex. Like making music with others, playing a collaborative game in a group means riffing on real-time events, timing one's actions to synchronise with others, guessing what they might do next; reciprocal sensitivities that create a strong and pleasing sense of synchrony, provding a particular kind of libidinally informed pleasure that is based on the twin pillars of ritual and mutuality. In addition to all this dancing, we are also offered impossible, idealized bodies to inhabit that promise to free us from our so fallible meat (don't worry I will refrain from the obvious extension here!). Yet at the same time such escapes works counter-wise to bring home the limitations and sensualities of the flesh.

Freud reminds us that human sexuality is complex, psychological and diversely invested. Could it be that the suffusion of libidinal energy within games is symptomatic of constraints on a more direct or even truer expression of sexual desire in popular culture? Could it be that we are now inheriting the outfall from the fact that games have tended to avoid 18 ratings because that would limit their market? Is the traditionally sexually conservative American market driving the sublimation of sex in games? The plethora of sexualised bodies and violent action that appears in games seem to be instantiations of the return of the repressed. Hollywood's Production Code in the early 1930s certainly produced a sublimation of sex into other charged images/themes, particularly in melodrama and screwball comedy, which often relied on innuendo to speak in code about sex to its audience. Freud argues that repressed sexual desires always find a way to be aired. Having said this, do we really want "groaning fornication" in games? Doesn't the erotic thrive on the veiled, the suggestive, the hidden and forbidden? The outcome of the veiling of sex does however reinforce inadvertently a "transgressive" rhetorics of sex and perhaps this is symptomatic of an unconscious need to preserve the frisson of sex afforded by such rhetoric?

Games do demand control of "lust", and games regularly rely on deferred gratification. Yet the promise of pleasure is always there, keeping us playing, hungry for more. Desire slaked is desire no more, gone its invigorating energy. 
Games provide us with machines for the perpetuation of desire. It is tempting to think that this is why there are quite a few sex management games on the market - these games make as their ludic mechanic the act of making, controlling and manipulating lust. Isn't that what we do when we defer gratification and keeping trying again when we play games? The lust balancing mechanic of 7 Sins then slots neatly in as a conceit about the nature of games and gaming. But before this gets carried away too far, this game makes use of age-old rhetoric sees sex "lustful", in need of control lest we will somehow become unanchored, adrift in a sea of sensual pleasures, lost to work and family ties. Yet isn't this why we play games? To lose our anchors? To experience immersion and flow? There is certainly some capital here in seeing games as desire machines. They promise us pleasure yet in return we subject ourselves to their rules and regimes of work. Many devices of compulsion get used in this process of seeking the ecstatic - allowing us to be beside ourselves, immersed in a game. And this is why it is valid to claims that games have libidinal economies.

Game sex has conditions which are indicative of the main ways in which sex is shaped by contemporary commerce and cultural values. It is acceptable when it is wrapped in the silks of romance as either theme, narrative or activity motivator. Transgression seems less of a condition, yet it is a major way in which sex is shown in popular culture is as sinful either in terms of exploitation or titillation, as carnival or comedy. These are generic means to render sex excitingly transgressive. We have also seen a more complex rhetoric of sex at work in games that do not show sex directly - the kinetic and gendered economy of tumescence and penetration. And in terms of playing games we subject ourselves to rules, we may think we are playing but we are played, our experience orchestrated as it might be in a bondage scene.

I hope that the increasing democratization of the tools used to make digital games results in greater diversity in the way they treat sex. Culturally there needs to be more widespread acknowledgement that sex is more complex than an "act" and that it might be regarded in ways other than as governed by a quantifiable drive. Designers also need to get beyond the anodyne romance model and the myth of complementarity to address the disturbing otherness of sex but without unreflexive recourse to clichéd rhetorics of exploitation. These moves will then provide an account of the complexity of human sexuality as means of countering sensationalist moral panic rhetorics about games. Making game sex in more diverse ways further enables designers to explore the potentialities of game media in relation to a core part of human life. And, finally, more broadly, such work would be part of a more general cultural process of engaging with, rather than disavowing, the radical strangeness of sex, desire and sexuality.

\section{Citations}

Aarseth, E. (1997). Cybertext: Perspectives on Ergodic Literature. NY: John Hopkins.

Atkins, B. (2006). What are we really looking at? The Future Orientation of Play. Games and Culture. Volume 1, No.2. April, 127-140.

Brathwaite, B. (2007). Sex in Video Games. Boston: Charles River Media.

Barker, M.; Petley, J. (Eds.) (2001). III Effects: The Media/Violence Debate. New York: Routledge. 2nd Edition.

Blackburn, S. (2004). Lust: The Seven Deadly Sins. Oxford: Oxford University Press.

Consalvo, M. (2003). Hot Dates and Fairy Tale Romances: Studying Sexuality in Video Games. In M.J.P. Wolf and B. Perron (Eds.). The Video Game Theory Reader. New York: Routledge.

Floyd, D. (2010). Animated Lectures on Videogame Issues. http://unrealitymag.com/index.php/2010/04/23/danielfloyds-animated-lecture-series-on-video-game-issues/. Accessed August 2010.

Gauntlett, D. (2005). Moving Experiences. Media Effects and Beyond. London: John Libbey, $2^{\text {nd }}$ edition.

Lacan, J. (1991). Le Séminaire. Livre XVII. L'envers de la psychanalyse, 1969-70. Ed. Jacques-Alain Miller. Paris: Seuil, 
Lyotard, J.-F. (1993). Libidinal Economy. London: Athlone Press.

Susan, S. (1982). The Pornographic Imagination. In A Susan Sontag Reader. Harmondsworth: Penguin.

Wirman, H. (2009). And he said, gasping, "Good... Excellent"'. Bad Games colloquium. 18 July 2009. University of the West of England 